
\title{
$\angle$ Research Square \\ The influence of supplier-user relationships on user satisfaction in the healthcare sector: the provisioning case.
}

\section{Milena Vainieri}

Scuola Superiore Sant'Anna

Lucrezia Coletta ( $\square$ lucrezia.coletta@santannapisa.it)

Scuola Superiore Sant'Anna https://orcid.org/0000-0001-7772-4224

\section{Chiara Seghieri}

Scuola Superiore Sant'anna - Polo Sant'Anna Valdera

\section{Research article}

Keywords: Customer satisfaction, Mediation model, Relationship Marketing, Healthcare, Provisioning

Posted Date: June 11th, 2020

DOI: https://doi.org/10.21203/rs.3.rs-32274/v1

License: (c) (i) This work is licensed under a Creative Commons Attribution 4.0 International License.

Read Full License 


\section{Abstract \\ Background}

Since 90 s customer orientation has become one of the main priorities in the public sector. While there are several studies dealing with final user satisfaction in the healthcare context, less attention has been given to inter-organizational relationships. This study aims at investigating the relationship between service quality, relationship quality and overall customer satisfaction in the case of a supplier-user provisioning service in the healthcare sector.

\section{Methods}

The analysis was based on a survey administered via CAWI (Computer Assisted Web Interviewing) to all professionals of the Tuscan health system. Moderation and mediation models were carried out to test the relationships between the three constructs, also differentiating among different customer typologies.

\section{Results}

Findings from the moderation model showed how different customers perceive relationship quality as differently influencing their overall satisfaction. This result was confirmed by the mediation models that showed how for one customer typology both relationship quality and service quality were relevant determinants of their satisfaction with supplier performance, even though relational aspects were more significant, compared to service aspects. Whereas, for the second customer typology overall satisfaction was influenced by characteristics concerning relationship quality only, suggesting that service quality dimension was not relevant in determining overall satisfaction.

\section{Conclusions}

In the healthcare provisioning case analyzed, different customers' typologies have different expectations and weigh differently service related and relationship related aspects. Supplier should use different levers in order to enhance customers' perceptions about the overall performance.

\section{Background}

A branch of Supply Chain Management focuses on the evaluation of supplier-buyer relationships, in order to understand the determinants of a successful relationship, especially in terms of long-term continuance of the relationship itself [1-4].

Two of the dimensions mostly investigated by scholars as influencing the success of business relationships are service quality and relationship quality. For example, Ulaga and Eggert [5] identified 
benefits and costs building the relationship value dimensions. Among the benefits, they mentioned service support and personal interaction as dimensions characterizing the relational aspect, in addition to more traditional dimensions characterizing the service quality aspect (product quality and delivery performance).

Scholars agree that the evaluation of business relationships should consider not only service quality aspects, but also customers' and suppliers' mutual perceptions related to the quality of the relationship. Indeed. as stated by Cannon and Perreault [6], "customer evaluations of supplier performance and satisfaction with relationship represent important outcomes in business exchange". Coherently, some researchers studied how to evaluate the performance of inter-organizational relationships, often stressing the importance of the relational dimension as a key determinant of the overall relationship performance. For example, Giannakis [4] proposed a framework for the assessment of the performance of supplier relationships, applicable both to the manufacturing and services contexts. This model took into consideration both the supplier and the customer perspectives, measuring their perceptions related to the nature of the relationship, the relational performance of the other party and their own relational performance.

Another example is the work by Benton and Maloni [2] that investigated the relationships between service outcomes, relationship quality, supplier satisfaction and relationship performance, both from the customer and the supplier perspective in the automobile sector. They discovered how the positive effect of service quality outcome on supplier satisfaction was completely mediated by the effect of supplierbuyer quality of relationship. This finding implies that in assessing overall performance of a relationship, what is most important is the relational dimensions, rather than the service outcome.

Most of the studies dealt with relationships belonging to the private sector. Whereas, in the public sector only few attempts have been made to investigate the performance of inter-organizational relationships in the supply chain context [7-8]. One example is a study [9] that developed a framework for the evaluation of the supply-chain performance in the healthcare sector.

As seen in this paragraph, the evaluation of supply chain relationships may be performed considering dyadic or network relationships, and focusing either on the supplier or on the buyer/customer perspective. The majority of studies focused on the customer (buyer) perspective for the evaluation of the relationship, because customer voice is deemed fundamental in order to improve the service quality provided. In particular, in inter-organizational contexts how to measure and use the customer voice is an issue both in public and private sector, since customer voice is considered as a proxy of the value created during the relational exchange between the two parties [10-11].

In this paper, a dyadic relationship between a supplier of medical products and a customer represented by the healthcare professionals that buy that products is investigated. A peculiarity of this study is that the relationship analyzed is a dyadic supply-chain relationship that belongs to the public sector sphere. In fact, in the public sector in general, and in the healthcare sector in particular, the majority of studies are focused on the evaluation of the relationship between a service provider (such as the health care 
professional) and the final customer (such as the patient), rather than on inter-organizational relationships. Also, in the public sector scholars mainly takes into consideration network relationships rather than dyadic ones [12-14].

This paper evaluates what occurs before the healthcare service is provided to the patient, in particular it investigates the provisioning service offered by a public organization to the healthcare professionals, from the perspective of the customer. More specifically, this work investigates the relationship between customer satisfaction, as perceived by the customer, and two of the main dimensions studied in relation to it, that are service quality and relationship quality. Moreover, the dyadic relationship is analyzed taking into consideration that different typologies of customers may evaluate differently the relationship with the supplier, since different customers have different needs and different expectations. Therefore, the analysis is conducted considering that the supplier establishes different relationships with different customers. This distinction also answers to the call [15-16] to consider contextual dimensions (such as the type of industry, the nature and intensity of the relationship, and the category of product or service under consideration), when analyzing the B-to-B relationships.

To conclude, this papers aims at understanding what determines customer satisfaction related to a provisioning public service and possible differences according to the customers' typology. The provisioning service is provided by a public organization in the healthcare sector (i.e. the supplier), while the customers are healthcare professionals who directly or indirectly interact with the supplier. In particular, this article first analyzes whether or not service and relationship quality have a different impact on the overall customer satisfaction, also by taking into account the typology of customer. Finally, through a mediation model, the relationship between service quality, relationship quality and overall satisfaction with the supplier is investigated.

\subsection{The supply chain in the Tuscan healthcare system}

In this paper, the focus of analysis will be the relationship between the public organization that is in charge of the provisioning service in the healthcare system of the Tuscany region, and health professionals who relate with it. Since 2015, all the provisioning activities in the Tuscan healthcare system are carried out by a single organization, called Estar, that has its own independence on administrative affairs, legal personality, management and accounting. Estar represents a unique experience in the Italian panorama, since it is not only in charge of the purchasing activities, but it has also to guarantee an integrated supply chain in the Tuscan healthcare system [17]. In addition to the provisioning activity, Estar is also responsible for the organization and fulfilment of the personnel recruitment and payment, public tendering, and information and communication technologies (ICT).

As regards the provisioning activity, Estar is in charge of the supply of several products, such as medical drugs, medical diagnostic devices, personal protection devices and administrative stuff and it became the unique supplier for all the healthcare authorities for the majority of products. Among the customers there are a plethora of different subjects (nurses, physicians, pharmacists, administrative staff, other health 
professionals, engineers, etc.), that can be divided in two groups: one composed by those subjects who have direct contacts with Estar, and the other one composed by those subjects who use the product provided by Estar, even if not interfacing directly with it. These two groups can be defined as the intermediaries and the end users, respectively. More specifically, intermediaries are direct customers since they are in charge of the product ordering, whereas the end users are indirect customers since they only use the products in their daily work activities. Therefore, end users do not relate with the supplier, rather with the intermediaries only. In the provisioning of the products, Estar has to guarantee not only service and product quality, but also support in managing the ordering procedure, in case the intermediator needs it. The latter aspect may be defined as the relational dimension, meaning that Estar has to be able to establish a good relationship with its customers, which entails being available when needed by the customer, and provide adequate answers to the customers' requests.

\section{Method}

\subsection{Hypotheses}

Relationship and service quality are constructs deeply investigated by scholars as key determinants for the overall customer satisfaction, along with trust, commitment, loyalty long-term orientation and power $[4,18-20]$. Therefore, B-to-B relationship between the healthcare supplier and the health professional customers was investigated, focusing on a public context, the Tuscan healthcare sector, rather than on a private one, as analyzed in the work by Benton and Maloni [2]. In particular, this research focused on the customer perspective, trying to understand what aspect is more relevant when the customer evaluates supplier performance. In other words, what determinant is mostly impacting on overall customer satisfaction was investigated.

Researchers in relationship marketing, deeply investigated the relationship between relationship quality, that is a relational outcome and an overall means of assessing the strength of a relationship between two firms [21], and service quality. In particular, relationship quality may be influenced by service quality, even though service quality can be considered a necessary but not sufficient, condition for relationship quality [22]. Given this premise, the first hypothesis tested is the following:

H1: Service quality has a positive impact on relationship quality.

A great body of literature has focused on the determinants of customer satisfaction, and in particular, some scholars have analyzed the relationship between service quality and customer satisfaction [21]. Although this relationship has been investigated in both directions, the majority of findings showed how service quality can be considered as an antecedent of customer satisfaction [23-25]. In fact, "[...] quality is one dimension on which satisfaction is based" [26]. Therefore, our second hypothesis is the following:

H2: Service quality has a positive impact on overall customer satisfaction. 
Wulf et al. [27] suggested how an improvement in relationship quality generates a higher level of satisfaction, trust, and commitment. Therefore, considering the first two hypotheses and the potential impact of relationship quality on overall customer satisfaction, the following third hypothesis is proposed:

H3: Overall customer satisfaction is influenced by service quality and relationship quality, even though relationship quality plays the main role.

Moreover, following the suggestion proposed by Ulaga and Eggert and Terpend et al. [15-16], this model for intermediary and end users was tested separately. In fact, there may be that customers, with different needs, and engaging in different kinds of relationships with the supplier, evaluate and weight differently the dimensions that determine the overall customer satisfaction.

\subsection{Questionnaire}

The questionnaire was developed in collaboration with experts of Tuscany Region Health System as well as Health Authorities (HAs) and Estar professionals. It was not a validated tool to assess general customer satisfaction, rather it was specifically designed to evaluate customer satisfaction in the healthcare context. The questionnaire was aimed at collecting and analyzing the customers' experiences (HAs) with the services provided by the supplier (Estar). In particular, in this article the focus is on a specific service: the provisioning. The provisioning section consists of 12 questions aimed at understanding the customer satisfaction in relation to both the service and the relationship quality.

The questionnaire was tested with some HAs' professionals in October 2017, and then administered in November 2017, via CAWI (Computer Assisted Web Interviewing) to all professionals who directly or indirectly (see in the paragraph 3.1 the details) interact with the supplier (Estar) in their daily work activities for a total of 2154 health professionals. The survey was opened for one month and a half to fill in the questionnaire. During this time period, two remainders were sent. Results were collected through the web-based software "LimeSurvey", and were then analyzed in aggregated form using Stata 12.

The overall response rate was about $31 \%$, that is coherent with response rates of other online surveys [28]. In particular, among the total number of respondents, only those health professionals who, during the last year, utilized, directly or indirectly, the services provided by Estar were took into consideration. Therefore, the respondents' population of interest consisted in 494 health professionals. In particular, 137 out of 494 were the end users group, whereas 357 out of 494 were the intermediaries group.

\subsection{Variables}

In this article, three constructs will be specifically analyzed: customer satisfaction with regards to service quality and relationship quality, and overall customer satisfaction with the supplier performance. The overall customer satisfaction with supplier performance was measured through a 1-5 Likert scale item, that asked the respondents to express the level of coherence between the overall service provided by the supplier and their expectations. 
The other two constructs were measured through two different groups of questions, that are reported in Table 1.

In the statistical model, the typology of customer, the intensity of needs, measured through the frequency of contacts that in the last year the customer had with the supplier, and the gender of respondents were also considered. A complete description of the variables is reported in Table 2.

The reliability of the constructs used to measure service quality and relationship quality was tested through the Cronbach's alpha. For the service quality and the relationship quality dimensions (described in Table 1) the Cronbach's alpha were 0,79 and 0,82, respectively, showing a more than acceptable internal consistency [29]. Moreover, an explorative factor analysis was conducted to identify the two underlying factors related to the different aspect of the consumer service quality and relationship quality. As one would expect, two factors were extracted from the analysis (eigenvalues $>1$ ), that are the service quality and the relationship quality factors, which accounted for about $55 \%$ and $66 \%$ of the total variance of the data.

Table 1 - Service and quality items

Service quality items
Scale adopted:
$.0-5 \%$
$.5-10 \%$
$.10-25 \%$
$.25-50 \%$
$.50-80 \%$
$.80-100 \%$

Relationship quality items Likert Scale 1-5 adopted:

On a scale from $0 \%$ to $100 \%$ express the following evaluations:

. 1=completely disagree

. 5=completely agree

1. $\%$ of times when the accompanying documents were not coherent with the order 2. $\%$ of times when at least one ordered product was missing

3. \% of time when it was necessary to repeat the order

4. $\%$ of times when it was necessary to order missing products with urgency

5. $\%$ of products not coherent with the order

6. \% of products missing

The following dimensions are respondent to the expectations:

1. Information on the availability of products in the warehouse

2. Tracking of the orders

3. Knowing who (among the supplier company) to call in case of need

4. Support provided by the supplier in solving problems related to the order management 


\begin{tabular}{|c|c|}
\hline Variable names & Variable description \\
\hline Overall satisfaction & Ordinal variable, taking on values $1-5$, where 1 represents the lowest level of satisfaction and 5 the highest one \\
\hline Service quality & Factor variable resulting from the factor analysis conducted for the group of items measuring service quality \\
\hline $\begin{array}{l}\text { Relationship } \\
\text { quality }\end{array}$ & Factor variable resulting from the factor analysis conducted for the group of items measuring relationship quality \\
\hline User & Dummy variable, equal to 1 if the customer is an end-user, O otherwise \\
\hline Service_user & Interaction term, given by the product of service quality and user variables \\
\hline Relationship_user & Interaction term, given by the product of relationship quality and user variables \\
\hline Frequency & $\begin{array}{l}\text { Categorical variable, taking on values } 1-\text {, that describes how many times in the last year the customer ordered something: } \\
\begin{array}{l}\text {. } \quad 1=\text { more than once a month } \\
\quad 2 \text { =once or more a month } \\
\text { 1. } 3=\text { less than once a semester }\end{array}\end{array}$ \\
\hline Gender & Dummy variable, taking on values equal to 1 if the respondent is a woman, 0 otherwise. \\
\hline
\end{tabular}

\subsection{Regression analyses}

As mentioned in Sect. 2.1, our research hypotheses aimed at investigating the relationship between service quality, relationship quality and overall customer satisfaction with supplier performance. As suggested by Ulaga and Eggert and Terpend et al. [15-16], relationship construct in B-to-B contexts, should be analyzed considering also contextual factors that might moderate or mediate the relationship quality evaluation. Following this suggestion, first the presence of a differentiated effects of service and relationship quality on overall customer satisfaction was checked, according to the typology of customer. In particular, the presence of a moderation effect played by the customer typology on the impact of service and relationship quality on the overall customer satisfaction was tested.

Then, a mediation model was applied, to investigate which dimension, among service and relationship quality, mostly impacts on the overall customer satisfaction with supplier performance. In other words, the interest was understanding whether the customer is mostly influenced by the relationship quality, rather than by the service quality, for the determination of her/his overall satisfaction with the supplier.

For the data analyses, two customer typologies were considered: the intermediaries and the end-users. In particular, the intermediaries include the following health professional figures: nurses, health assistants, pharmacists, and laboratory technicians. All these professional figures are responsible for directly interacting and communicating with the supplier, since they have to make the product orders and have access to the whole tracking process. Whereas, physicians, biologists, physicists, speech therapists, psychologists and veterinarians are the end users, who do not directly engage with Estar, rather they make their requests to the intermediaries, and then use the products, that the intermediary has ordered. 
The two customer typologies are mutually exclusive, so that a health professional identified as an intermediary was not also included in the analysis as an end user, and vice versa.

To test the three hypotheses and the mediation effect of relationship quality on overall customer satisfaction, a regression analysis drawing from Baron and Kenny's mediation model [30] was conducted. The following three conditions must hold in order to have a mediation effect:

1. The independent variable (service quality) should be significantly related to the mediator (relationship quality).

2. The independent variable (service quality) should be significantly related to the dependent variable (overall customer satisfaction).

3. The mediator should be related to the dependent variable when the independent variable is also included in the model. In order to establish a mediation effect, the relationship between the independent variable (service quality) and the dependent variable should be reduced (partial mediation) or should not be no longer statistically significant (full mediation), when controlling for the mediator (relationship quality).

The general mediation model tested is the following:

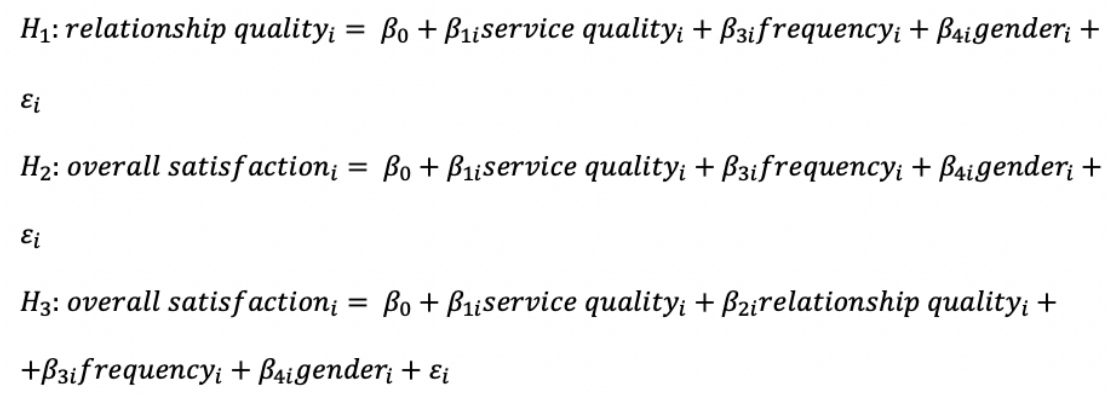

A complete description of the variables included in the mediation model is provided in Table 1 of the Appendix. For the regression analyses, the respondents declaring they were not able to provide an assessment to the overall satisfaction with the supplier services were discarded and considered as missing values. That means the $8 \%$ of the end users and the $3 \%$ of intermediaries did want (or were not able) to evaluate the overall performance of the supplier (satisfaction with Estar). However, nonrespondents did not significantly differ from respondents in terms of individual characteristics (gender, products ordered, frequency of relationship), so results are not affected by sample bias.

The second and the third equations have been estimated through an ordered logit regression model, since the dependent variable (i.e. the overall satisfaction with the supplier performance) is an ordinal variable, where 1 represents the lowest level of satisfaction and 5 the highest one.

\section{Results}


As regards the intensity of needs of the customers (measured through the frequencies of requests made in 2017) showed how the majority of respondents $(60 \%)$ made a request to the supplier more than once a month, $19 \%$ less than once a month, $21 \%$ less than once a semester. Finally, women represented $64 \%$ of total respondents.

First of all, it was analyzed whether or not the customer typology moderated the relationship between service and relationship quality (the independent variables) on the overall customer satisfaction with the customer. By doing so, two interaction terms were created, one composed by the typology of user and the service quality dimension, and the other one composed by the typology of user and the relationship quality dimension. Then, an ordered logistic regression, was performed, where the dependent variable was the overall customer satisfaction, the independent variables were service and relationship quality, the typology of user and the two interaction terms, whereas gender and intensity of relationship were included as control variables.

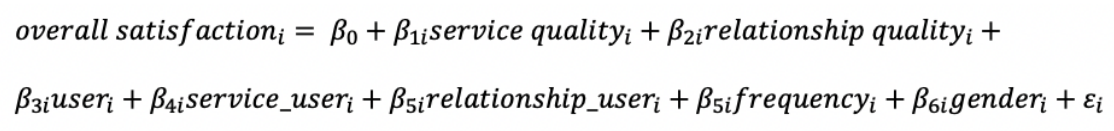

Results in Table 3 show how the customer typology moderates the effect of relationship quality on the overall satisfaction. In particular, even if both end-users and intermediaries perceive relationship quality as an important dimension influencing their overall satisfaction (odds ratio (OR) for relationship quality is positive and statistically significant), end-users consider relationship quality as two times more important in determining their overall satisfaction with the supplier, as compared to intermediaries. Whereas, this moderation effect does not hold for the service quality dimension, meaning that the influence of service quality on the overall satisfaction is relevant (the OR for service quality is positive and statistically significant) even though almost equal among different customers. Finally, neither the gender nor the intensity of relationship seem to influence overall customer satisfaction.

Subsequently, a mediation model was tested hypothesizing that the effect of service quality on overall customer satisfaction is mediated by the relationship quality dimension.

Therefore, a mediation analysis through three sets of regression was performed, as reported in Sect. 2.5. The regression models were run separately by the customer typology (i.e. intermediaries and end-users) to control for the above mentioned moderation effect.

As regards the intermediaries, the three hypotheses were accepted, hence results reported in Table 4 show that relationship quality positively but only partially affects the impact of service quality on overall customer satisfaction with supplier performance (Model 3). Findings suggest that both relationship and service quality are relevant for the customer in determining the overall satisfaction with the supplier, even though relationship quality has a higher impact on the outcome, compared to service quality. However, even though relationship quality plays the main role in determining the overall satisfaction, intermediaries still perceive service quality as a significant dimension of evaluation. This finding may be explained by 
the fact that intermediaries are those customers who deeply know the entire provisioning process, including delivery times, typologies of products requested, quantities and quality ordered. Hence, they can properly evaluate the service quality provided by Estar, and they are more sensitive to the supplier performance related to the service offered.

Finally, a mediation model for the end-users was estimated, for whom results show a different dynamic. In fact, relationship quality for end-users seems to completely and positively mediate the relationship between service quality and overall satisfaction, since the OR for service quality is not statistically significant (Table 5 - Model 3). In other words, in determining end-users' overall satisfaction with Estar performance, relationship quality, rather than service quality, plays a significant role. This is an interesting result, since it seems to indicate that the end-user, who is not aware about the proper provisioning process functioning, considers only relationship quality aspects as relevant for her/his overall satisfaction with the supplier. For example, in the determination of the overall satisfaction, since end-users do not engage in direct relationships with the supplier, they may be entirely influenced by the reported dissatisfaction expressed by intermediaries. Therefore, they do not evaluate service quality dimension as relevant in the determination of their overall satisfaction (since they do not know the service process and its details), rather they perceive the relational aspect as the most significant one.

Comparing the ORs of relationship quality for intermediaries and end-users (Model 3), one can see how the OR for end-users is significantly higher than the one for intermediaries. Whereas, as regards the ORs of service quality, they do not significantly differ among the customer typologies. These findings are coherent with the results coming from the moderation model (Table 3), that showed how for end-users the relationship quality dimension is more crucial, compared to intermediaries, for determining their overall satisfaction with the supplier. On the other hand, the two groups of customers consider service quality as an equally important determinant of satisfaction.

Finally, as regards the variables controlling for the frequency of relationships and the gender, their ORs are not statistically significant neither for intermediaries nor for end users.

Table 3 - Results of the moderation model 


\begin{tabular}{|ll|}
\hline Dependent variable: overall customer satisfaction \\
\hline Independent variables & Odds ratio \\
\hline Service quality & $1.67 * * *$ \\
Relationship quality & $7.56^{* * *}$ \\
User & 1.03 \\
Service_user & 0.78 \\
Relationship_user & $2.57 * * *$ \\
Frequency (category=2) & 1.08 \\
Frequency (category $=3$ ) & 0.62 \\
Gender & 0.85 \\
\hline$* * *$ p-value $<0.01$ & \\
\hline$* *$ p-value $<0,05$ & \\
\hline
\end{tabular}

Table 4 - Mediation model for intermediaries

Model 1 (H1)

Model 2 (H2)

Model 3 (H3)

\begin{tabular}{|c|c|c|c|c|c|}
\hline \multicolumn{2}{|c|}{ Dependent variable: relationship quality } & \multicolumn{2}{|c|}{$\begin{array}{c}\text { Dependent variable: overall customer } \\
\text { satisfaction }\end{array}$} & \multicolumn{2}{|c|}{$\begin{array}{c}\text { Dependent variable: overall customer } \\
\text { satisfaction }\end{array}$} \\
\hline Independent variables & $\begin{array}{l}\text { Linear regression } \\
\text { coefficients }\end{array}$ & Independent variables & Odds ratio & Independent variables & Odds ratio \\
\hline Service quality & $0.30^{* * *}$ & Service quality & $2.20^{* * *}$ & Service quality & $1.63^{* * *}$ \\
\hline Relationship quality & - & Relationship quality & - & Relationship quality & $7.52 * * *$ \\
\hline Frequency (category $=2$ ) & 0.099 & Frequency (category=2) & 1.24 & Frequency (category=2) & 1,12 \\
\hline Frequency (category $=3$ ) & -0.24 & Frequency (category=3) & 0.53 & Frequency (category $=3$ ) & $0.43^{*}$ \\
\hline Gender & -0.03 & Gender & 0.97 & Gender & 0.87 \\
\hline$* * *$ p-value $<0.01$ & $\mathrm{n}=\mathbf{2 9 9}$ & & $n=318$ & & $\mathrm{n}=\mathbf{2 9 9}$ \\
\hline
\end{tabular}

Table 5 - Mediation model for end-users 


\begin{tabular}{|c|c|c|c|c|c|}
\hline \multicolumn{2}{|c|}{ Model 1 (H1) } & \multicolumn{2}{|c|}{ Model 2 (H2) } & \multicolumn{2}{|c|}{ Model 3 (H3) } \\
\hline \multicolumn{2}{|c|}{ Dependent variable: relationship quality } & \multicolumn{2}{|c|}{$\begin{array}{c}\text { Dependent variable: overall customer } \\
\text { satisfaction }\end{array}$} & \multicolumn{2}{|c|}{$\begin{array}{c}\text { Dependent variable: overall customer } \\
\text { satisfaction }\end{array}$} \\
\hline Independent variables & $\begin{array}{l}\text { Linear regression } \\
\text { coefficients }\end{array}$ & Independent variables & Odds ratio & Independent variables & Odds ratio \\
\hline Service quality & $0.52 * * *$ & Service quality & $2.7^{* * *}$ & Service quality & 1.50 \\
\hline Relationship quality & - & Relationship quality & - & Relationship quality & $24.51 * * *$ \\
\hline Frequency (category=2) & -0.09 & Frequency (category=2) & 1.13 & Frequency (category=2) & 1.24 \\
\hline Frequency (category=3) & 0.05 & Frequency (category=3) & 1.27 & Frequency (category $=3$ ) & 0.90 \\
\hline Gender & 0.12 & Gender & 1.14 & Gender & 0.77 \\
\hline$* * *$ p-value $<0.01$ & $\mathrm{n}=\mathbf{8 3}$ & & $\mathrm{n}=91$ & & $\mathrm{n}=\mathbf{8 2}$ \\
\hline
\end{tabular}

\section{Discussion}

This paper was aimed at understanding the role played by relationship quality and service quality in the generation of the overall satisfaction as perceived by a business customer. The relationship considered is a dyadic business relationship occurring between a public supplier of medical products and the healthcare professionals (customers) who need these products.

In particular, following the suggestion by Garbarino and Johnson [31] bout the different role of relationship intensity on overall satisfaction, commitment and trust, first the moderation effect played by customer typology on the relationship between service and relationship quality on overall customer satisfaction with the supplier services was analyzed. Then, given the presence of the moderation effect, a mediation analysis was performed, differentiating among the two typologies of customers, that are the intermediaries (who have direct contact with the supplier) and the end-users (who have indirect contact with the supplier). It can be noticed: a) a positive and significant effect played by service quality on relationship quality; $b$ ) the positive influence played separately by service quality and relationship quality on overall satisfaction; and c) the significant and positive impact of service quality on overall satisfaction that is partially mediated by the impact of relationship quality for intermediaries and totally mediated for end-users, when both service and relationship quality are included in the model. These findings may be explained by the fact that intermediaries are perfectly aware of the entire process of provisioning and they directly engage with the supplier, hence service quality aspects, such as delivery times, quantitative and qualitative appropriateness of the products with the orders, and so on, are perceived as important features composing their overall satisfaction. However, they seem to attribute more significance to relational quality aspects, such as the ability of the supplier to promptly and effectively respond and satisfy any additional requests of support. To conclude, for intermediaries, relationship quality, rather than service quality, seems to be the dimension that mostly impacts on their overall satisfaction with supplier performance, and this occurs regardless of the product category, the frequency of relationships, or the gender.

Whereas, as regards the end-users, the mediation is complete, meaning that relationship quality dimension totally mediates the effect of service quality on overall customer satisfaction. In other words, end users' overall satisfaction seems to be influenced by relationship quality characteristics only, rather than a combination of relationship and service quality aspects. This finding may be explained by the fact 
that end users do not have direct contacts with the supplier, and consequently the worth of mouth took the advantage of the real service quality outcome. Hence, the overall satisfaction with supplier is not influenced by an evaluation on service quality, rather it is affected by relational aspects only. Coherently with this argumentation, also for end users, this result is not dependent on the product category or the frequency of relationships. Moreover, another interesting finding has emerged from the descriptive statistics: about one third of the end users are not able to express an evaluation on the overall performance of the supplier. This reinforces the hypothesis that end users are not completely aware of the provisioning functioning, and hence they are not always able to evaluate the overall supplier performance, those who did are often based on the worth of mouth opinions which are particularly important when the assessment is negative [32].

From one side one would have expected that relationship quality had a higher mediation effect between overall satisfaction and service quality in the case of intermediaries because of the intensity of contacts [31]. From the other side, given the high role played by relationship quality for end-users, the word of mouth seems to play a very important role since it totally mediates the perception of the service quality.

\section{Conclusions}

This study contributes to the literature by dealing with an under-investigated topic in the supply-chain management that is the investigation of the determinants of business customer satisfaction [11] in a dyadic public sector context. Indeed, differently from previous public sector studies that focused on network relationships, this paper proposes an empirical analysis on a dyadic supplier-customer relationship in the healthcare provisioning context.

These findings contribute to the present body of literature on healthcare management, providing not only a particular view on supplier-customer relationship in the healthcare sector, but also shedding light on relational peculiarities that occur when accounting for different customer typologies. In fact, depending on the particular kind of customer, the relationship that the customer will engage with the supplier will be different, and therefore the factors mostly influencing the determination of the overall satisfaction with the supplier performance will also be different, according to the customer typology.

Given these findings, practical implications refer to the fact that although both users' typologies are important, supplier should adopt different levers in order to enhance customers' perceptions about the overall performance.

Future research should investigate these relationships also considering other aspects analyzed in the literature such as trust, power, cooperation and long term orientation [21,33-36]. Moreover, the model developed and analyzed in this paper could benefit from the inclusion of the direct relationship between intermediaries and end users, in order to properly disentangle the satisfaction of end users with the supplier performance from the one with intermediaries. Finally, even though there is the need to confirm this evidence also in other contexts and sectors in order to obtain generalizable results, to the best of our 
knowledge, this study represents the first explorative attempt to analyze B-to-B relationships in the provisioning service of the healthcare system.

\section{Abbreviations}

CAWI: Computer Assisted Web Interviewing; Estar: Ente di supporto tecnico-amministrativo regionale; HA: Health Authority; ICT: information and communication technologies; OR: Odds ratio; OSS: Operatori sociosanitari.

\section{Declarations}

\section{Ethics approval and consent to participate}

Not applicable

Consent for publication

Not applicable

\section{Availability of data and materials}

The datasets used and/or analyzed during the current study are available from the corresponding author on reasonable request.

\section{Competing interests}

The authors declare that they have no competing interests.

\section{Funding}

Not applicable

\section{Authors' contributions}

MV and LC designed the study, LC, MV and CS analyzed data. All authors contributed to writing and interpreting the results. All authors read and approved the final manuscript.

\section{Acknowledgements}

Not applicable

\section{References}

1. Parsons AL: What determines buyer-seller relationship quality? An investigation from the buyer's perspective. J supply chain manag. 2002, 38(1), 4-12. 
2. Benton WC, Maloni, M: The influence of power driven buyer/seller relationships on supply chain satisfaction. J oper manag. 2005, 23(1), 1-22.

3. Zhao X, Huo B, Flynn BB, Yeung JHY: The impact of power and relationship commitment on the integration between manufacturers and customers in a supply chain. J oper manag. 2008, 26(3), 368-388.

4. Giannakis M: Performance measurement of supplier relationships. Supply chain manag. 2007, 12(6), 400-411.

5. Ulaga W, Eggert A: Value-based differentiation in business relationships: Gaining and sustaining key supplier status. J marketing. 2006, 70(1), 119-136.

6. Cannon JP, Perreault Jr WD: Buyer-seller relationships in business markets. J marketing res . 1999, 439-460.

7. McKone-Sweet KE, Hamilton P, Willis SB: The ailing healthcare supply chain: a prescription for change. J supply chain manag. 2005, 41(1), 4-17.

8. Lai KH, Ngai EWT, Cheng TCE: Measures for evaluating supply chain performance in transport logistics. Transport res e-log. 2002, 38(6), 439-456.

9. Lega F, Marsilio M, Villa S: An evaluation framework for measuring supply chain performance in the public healthcare sector: evidence from the Italian NHS. Prod plan control. 2013, 24(10-11), 931-947.

10. Pollitt C, Dan S: The Impacts of the New Public Management in Europe: A Meta-analysis. Coordinating for Cohesion in the Public Sector of the Future, 2011. Web.

11. Mustak M, Jaakkola E, Halinen A, Kaartemo V: Customer participation management: developing a comprehensive framework and a research agenda. J serv manage. 2016, 27(3), 250-275

12. Cepiku, D: Performance management in public administrations. Handbook of Global Public Policy and Administration. 2017.

13. Montoya LA, Montoya I, González OS: Lessons from collaborative governance and sociobiology theories for reinforcing sustained cooperation: a government food security case study. Public health. 2015, 129(7), 916-931.

14. Provan KG, Milward HB: A preliminary theory of interorganizational network effectiveness: A comparative study of four community mental health systems. Admin sci quart. 1995, 1-33.

15. Ulaga W, Eggert A: Relationship value in business markets: the construct and its dimensions. J busbus mark. 2005, 12(1), 73-99. 
16. Terpend R, Tyler BB, Krause DR, Handfield RB: Buyer-supplier relationships: Derived value over two decades. J supply chain manag. 2008, 44(2), 28-55.

17. Rapporto OASI 2017- Osservatorio sulle Aziende e sul Sistema sanitario Italiano", CERGAS SDA Bocconi. 2017 https://www.cergas.unibocconi.eu/wps/wcm/connect/bbcced3a-6990-478d-b190d3b1bfc35377/Indice.pdf?MOD=AJPERES\&CVID =mdPQe01\&CVID =mdPQe01\&CVID=mdPQe01

18. McDougall GH, Levesque T: Customer satisfaction with services: putting perceived value into the equation. J serv mark. 2000, 14(5), 392-410.

19. Brown JR, Lusch RF, Nicholson CY: Power and relationship commitment: their impact on marketing channel member performance. J retailing. 1995, 71(4), 363-392.

20. Michie DA, Sibley SD: Channel member satisfaction: controversy resolved. J acad market sci. $1985,13(2), 188-205$.

21. Chumpitaz-Caceres R, Paparoidamis NG: Service quality, relationship satisfaction, trust, commitment and business-to-business loyalty. Eur j marketing. 2007, 41(7/8), 836-867.

22. Crosby LA, Evans KR, Cowles D: Relationship quality in services selling: an interpersonal influence perspective. J marketing. 1990, 68-81.

23. Dick AS, Basu K: Customer loyalty: toward an integrated conceptual framework. J acad market sci. 1994, 22(2), 99-113.

24. Anderson EW, Fornell C, Lehmann DR: Customer satisfaction, market share, and profitability: Findings from Sweden. J marketing. 1994, 53-66.

25. Cronin Jr JJ, Taylor SA: Measuring service quality: a reexamination and extension. J marketing. 1992, 55-68.

26. Rust RT, Oliver RL: Should we delight the customer?. J acad market sci. 2000, 28(1), 86.

27. Wulf KD, Odekerken-Schröder G, lacobucci D: Investments in consumer relationships: A cross-country and cross-industry exploration. J marketing. 2001, 65(4), 33-50.

28. Cook, C., Heath, F., \& Thompson, R. L. (2000). A meta-analysis of response rates in web-or internetbased surveys. Educational and psychological measurement, 60(6), 821-836.

29. Peterson RA: A meta-analysis of Cronbach's coefficient alpha. J consum res. 1994, 21(2), 381-391.

30. Baron RM, Kenny DA: The moderator-mediator variable distinction in social psychological research: Conceptual, strategic, and statistical considerations. J pers soc psychol. 1986, 51(6), 1173. 
31. Garbarino E, Johnson MS: The different roles of satisfaction, trust, and commitment in customer relationships. J marketing. 1999, 63(2), 70-87.

32. Söderlund M: Customer satisfaction and its consequences on customer behaviour revisited. Int j serv ind manag. 1998.

33. Abdallah AB, Abdullah MI, Mahmoud-Saleh FI: The effect of trust with suppliers on hospital supply chain performance: the mediating role of supplier integration. Benchmarking: An International Journal. 2017, 24(3), 694-715.

34. Lam SY, Shankar V, Erramilli MK, Murthy B: Customer value, satisfaction, loyalty, and switching costs: an illustration from a business-to-business service context. J acad market sci . 2004, 32(3), 293-311.

35. Ganesan S: Determinants of long-term orientation in buyer-seller relationships. the $\mathrm{J}$ marketing. 1994, 1-19.

36. Skinner SJ, Gassenheimer JB, Kelley SW: Cooperation in supplier-dealer relations. J retailing. 1992, 68(2), 174-193. 